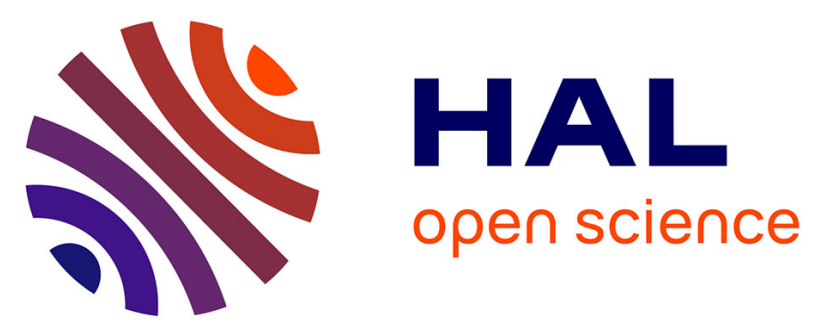

\title{
Architectural analysis of herbaceous crop species: a comparative study of maize (Zea mays L.) and garden pea (Pisum sativum L.)
}

Bruno B. Moulia, Claude Edelin, Caroline Loup, Marie-Hélène Jeuffroy

\section{- To cite this version:}

Bruno B. Moulia, Claude Edelin, Caroline Loup, Marie-Hélène Jeuffroy. Architectural analysis of herbaceous crop species: a comparative study of maize (Zea mays L.) and garden pea (Pisum sativum L.). Agronomie, 1999, 19 (3-4), pp.305-312. hal-00885932

\section{HAL Id: hal-00885932 https://hal.science/hal-00885932}

Submitted on 1 Jan 1999

HAL is a multi-disciplinary open access archive for the deposit and dissemination of scientific research documents, whether they are published or not. The documents may come from teaching and research institutions in France or abroad, or from public or private research centers.
L'archive ouverte pluridisciplinaire HAL, est destinée au dépôt et à la diffusion de documents scientifiques de niveau recherche, publiés ou non, émanant des établissements d'enseignement et de recherche français ou étrangers, des laboratoires publics ou privés. 


\title{
Architectural analysis of herbaceous crop species: a comparative study of maize (Zea mays $L$. and garden pea (Pisum sativum L.)
}

\author{
Bruno Moulia $^{\text {a* }}$, Claude Edelin ${ }^{\mathrm{b}}$, Caroline Loup ${ }^{\mathrm{b}}$, Marie-Hélène Jeuffroy ${ }^{\mathrm{c}}$ \\ ${ }^{a}$ UR Bioclimatologie, Inra, 78850 Thiverval-Grignon, France \\ ${ }^{\mathrm{h}}$ Laboratoire de botanique, UMR 5554 (CNRS/Université de Montpellier II), 163, rue A. Broussonet, 34090 Montpellier, France \\ 'UR Agronomie, Inra, 78850 Thiverval-Grignon, France
}

(Received 25 September 1998; accepted 16 February 1999)

\begin{abstract}
Some results of the application of the method of architectural analysis, originally designed for trees, to crop species are reviewed. They are illustrated through a comparison between two species, maize (Zea mays L.) and pea (Pisum sativum L.). It is shown that despite huge apparent differences in physiognomy, similarities in architectural development can be found, and expressed within the framework of architectural analysis. The relevance of these results for architectural modelling, crop ecophysiology and architectural studies is discussed. It is argued that one of the main benefits of an interdisciplinary approach probably is at the inter-specific comparative level, and that it may allow for the development of rather general structure-function architectural models, with a clarification of significant specific traits. ( Inra/Elsevier, Paris.)
\end{abstract}

Zea mays L. / maize / Pisum sativum L. / garden pea / morphology / architecture / plasticity

Résumé - Analyse architecturale des herbacées cultivées. Cet article présente une illustration des premiers acquis de l'application de l'analyse architecturale, initialement développée pour les ligneux, à des espèces herbacées cultivées, à partir de la comparaison de deux espèces, le maïs (Zea mays L.) et le pois (Pisum sativum L.). Malgré d'évidentes différences physionomiques, des similitudes de développement architectural, correspondant à des concepts d'analyse architecturale, existent. La signification de ces résultats pour la modélisation architecturale, l'agrophysiologie et l'architecture des plantes sont discutées. Il semble que le principal bénéfice d'une telle approche interdisciplinaire réside dans la mise en place d'une écophysiologie développementale comparée (entre espèces). Ceci devrait permettre le développement de modèles structure-fonction architecturaux assez généraux, avec une meilleure identification des caractéristiques spécifiques. (@ Inra/Elsevier, Paris.)

Zea mays L. / maïs / Pisum sativum L. / pois / morphologie / architecture / plasticité

Communicated by Gérard Guyot (Avignon, France)

* Correspondence and reprints: SEPF, Inra, 86600 Lusignan, France

moulia@lusignan.inra.fr 


\section{Introduction}

Within the last few decades, most of the crop physiological models have considered the plant as a set of compartments, driven by a general phenological clock (see a review in [2]). The compartments were usually defined on a morphological basis, either at the level of the system (i.e. shoot system, root system, reproductive system), or at the level of the organ (i.e. leaf, stem, fruits and seeds, root). In this last case, it was implicitly assumed that the populations of organs were homogeneous in terms of their dynamic responses to environmental factors, or at least that the effect of heterogeneity was of second order. Aside from such process models, demographic studies have been developed, detailing the age structure of the organ populations during the development of the plant [11], but with little attention to the possible differentiation of plant parts, irrespective of their age (but see [3, 14]). However, recent advances in ecophysiological studies of the control of plant development have indicated that plant parts can differ in their response to their local environment, irrespective of their age. For example, the photomorphogenetic control of stolon development in clover is stolon-type dependant, yielding marked differences in morphology and spatial colonisation in response to homogeneous treatments [8].

Such considerations help to explain the current revival of interest in morphological studies in agronomical sciences, and the development of architectural modelling in crop species. However, with the exception of phenology (e.g. [12]) a large part of our knowledge about the morphological development of crop species is still framed within the monographics studies from the first half of this century [22]) with a particular attention to shoot and root growth and anatomy.

Meanwhile, in trees and shrubs, methods of architectural analysis of global plant construction and patterning have been renewed since the 1980 s, under the influence of the seminal work by Hallé, Oldeman and co-workers [9] and their concepts of architectural models (see $[1,6,20]$ for detailed reviews). These analyses have mainly considered the plant as a set of axes. Each axis has been defined as the morphological sequence of phytomer units (leaf, internode, axillary bud), along the same general smooth direction, resulting from one (monopodial) or more (sympodial) meristems [20]. The architectural development of a plant then results from i) the modalities of axes morphological construction, ii) their differentiation (leading to different morphogenetical types of axes) and iii) their patterning within the plant (see [1] and [6] for more detailed demonstrations of the method of morphological analysis of plant construction). The comparison of the architectural analyses of many different species have made it possible to establish general processes of plant construction. Some of these architectural concepts have been implemented as a basis of architectural models of tree development [4].

To our knowledge, only a few attempts have been made to apply the methods of architectural analysis to herbaceous plants, and the most systematic work goes back to the very preliminary stages of architectural analysis $[1,10,20]$. For that reason, a set of studies on eight crop species from the Poaceae and Fabaceae (= Leguminosae) families was conducted to evaluate the relevance of architectural analysis applied to crop species. This paper focuses on a comparison between two species (one from each family), maize (Zea mays L.) and pea (Pisum sativum L.).

\section{Materials and methods}

\subsection{Plant material}

Detailed descriptions of the experimental conditions have been published previously [15, 19, 23]. Briefly, the plants were grown from seeds in normal field conditions in Grignon (France $48^{\circ} 51^{\prime} \mathrm{N}, 1^{\circ} 58 \mathrm{E}, 105 \mathrm{~m}$ in height). In both species a typical modern cultivar was used: Dea (mid early flowering flint dent hybrid) in maize and Solara (semi-afila type) in pea. Two types of experimental plots were constructed. In the first one, called 'isolated plants', the plants were grown at extremely low density (about 0.40 $\mathrm{m}$ between plants in pea, and $1.20 \mathrm{~m}$ in maize) and watered liberally to enable a very large architectural development. The second type, called hereafter 'high density', consisted of 'normal' agricultural fields, with plants at a range of plant densities from 45 to 90 plants $\mathrm{m}^{-2}$ for pea and from 10 to 20 plants $\mathrm{m}^{-2}$ in maize, in irrigated conditions. Note that our aim here was not to make a quantitative assessment of the response to plant density (and the influence of spatial sawing patterns, e.g. [23]), but by comparing extreme situa- 
tions, to test whether the architectural analysis could give better insights into the specification of the major developmental responses.

\subsection{Morphological study}

Plants (20 per species and treatment) were studied at five to six developmental stages, from seedlings to seed production, in order to encompass the whole vegetative developmental cycle of the plant. Each plant was carefully observed, and a sub-sample of five plants was dissected (to study the buds and the hidden organs). Profile stick diagrams and plant diagrams were realised to capture the morphology of the organs, and their relative positions (see Methods of description in Bell [1] for more details about the methods of morphological description). Moreover, detailed drawings were made for every peculiar trait (figure 1).

From the comparative analysis of all this material, a synthetic diagram was established, corresponding to the typical 'mean' individual of the species in a given environmental condition. In such diagrams, the leaves are represented by symbols, in order to minimise the specific morphological traits and make the comparison between species easier.

\subsection{Architectural analysis}

A recent review of the concepts and tools of architectural analysis is given in Edelin et al. [6], and a larger historical view can be found in Bell [1]. However, due to the fact that such analysis is not well known in the agronomical field, a brief and partial introduction is given here. The first step of the analysis is to categorise the axes from the clustering of 25 different morphological traits (e.g. sympodial or monopodial growth, indeterminate or determinate growth, phyllotaxy, tropisms, markers of phases of reduced elongation, bud morphology, sequence of branching, position of sexual organs, position of root initials, adventive rooting, sizes and shapes of organs, etc.), in an attempt to distinguish different modes of morphogenetical differentiation. The major functions of these axes are also determined qualitatively (support, exploration, exploitation, reserve, reproduction). The second step focuses on the plant construction sequence, i.e. i) topographical patterning of the axes in the branched structure, ii) sequence of outgrowth, and iii) main phenological events. These aspects are interpreted in terms of morphogenetical correlations (dependence of the morphogenetic differentiation of an axis on the state of development of the parent plant) [16], and accordingly, a (morphogenetical) hierarchy is defined between the types of axes. The hierarchical architecture including all the types of axes represents the 'architectural unit' of the species [5]. Functionally, the completion of the architectural unit corre-

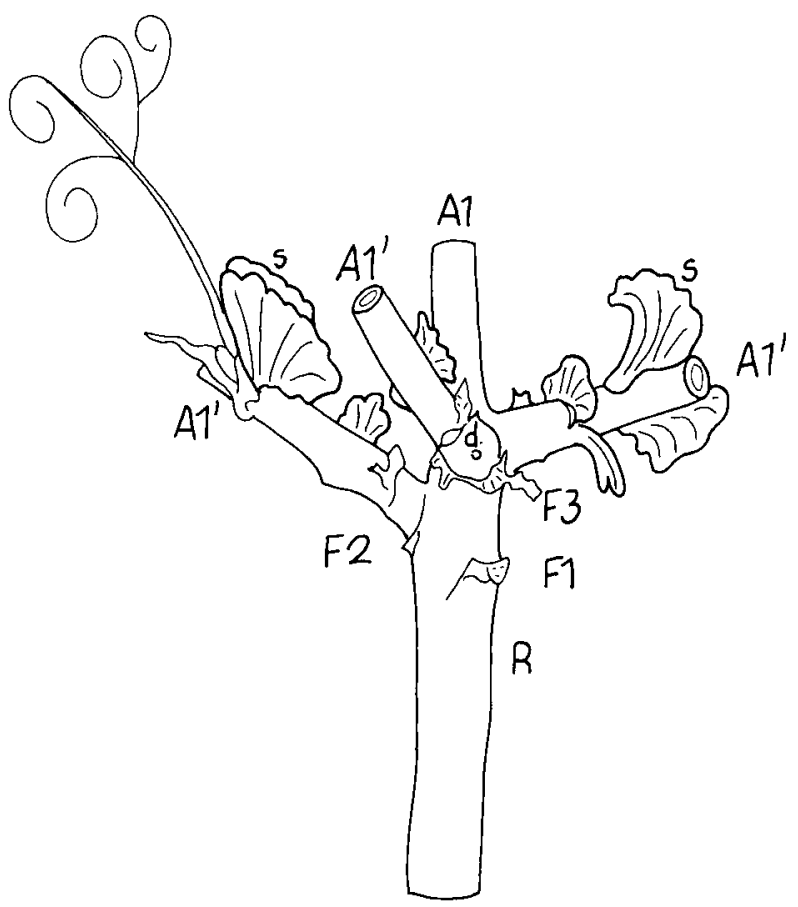

Figure 1. Example of a morphological detailed drawing: a view of the basal part of the main axis of a pea plant.

$\mathrm{A} 1$, main axis; Fn, leaf number $n$; $\mathrm{S}$, stipule; $\mathrm{R}$, root collar, Al', basal reiterates (note that they are borne by the same node); d, dead axillary bud (the nomenclature of axes and the definition of reiteration are detailed latter on in the text).

sponds to the stage where the plant is able to perform all its functions.

In most species, the process of building an architectural unit can be (partially or totally) repeated, eventually several times. This process has been called 'reiteration' [17]. Several modes of reiterations (sylleptic, proleptic) have been found, which can eventually induce changes in the morphogenetical and functional organisation of the plant [6].

As the development of the plant (particularly the reiterative process) is very dependant on the environmental conditions, it is thus necessary to begin the study on isolated plants in favourable conditions so that the total development can be studied. In a second time, the variability of architectural development induced by environmental conditions (in our case, by plant density) can be described and interpreted [13].

Before reviewing the cases of maize and pea, it should be stated that the previous presentation of architectural analysis has been given here for the non-specialist reader. This does not mean that we assumed that these concepts, 
developed from the observation of a large collection of tree species, can be readily extended to the herb species we have studied. Although they were familiar to some of us, we have tried to begin our analysis from 'scratch' on a morphological basis, in all the species we have studied. The relevance of the architectural analysis in interpreting these plants was tested subsequently.

\section{Results}

\subsection{Maize architecture}

A detailed morphological, kinetic and architectural analysis of maximal maize development is being published elsewhere. Here, the aim is to review only the morphological aspects necessary to discuss the architectural analysis, and to allow for a comparison between species.

The maize plant is composed of two categories of axes (figure 2). The primary axis (A1) is monopodial and orthotropic. It displays a distichous phyllotaxy, with one bud at the axil of each leaf, with the exception of the five to six terminal nodes. Its growth is determinate, ending with a terminal inflorescence (panicle). The basal part of the Al axis is strictly vegetative, with short internodes and adventitious roots. The upper part displays much longer internodes, bears axillary A2 axes (in isolated plants, any node higher than node 5 usually bore one) and is deprived of roots (although meristematic rings can be found at the base of each internode).

The A2 axes are short, with very short internodes. However the pattern of internode relative lengths is very different, with a (relatively) long first internode. They are also monopodial, with a distichous phyllotaxy, except for the last few leaves where there is a shift to a spiral pattern. In isolated plants, the vegetative nature of the A2 leaves, including lamina and sheath was clear, and a normal axillary bud was found in the basal part of the axis. The A2 axes have a definite growth, ending with a female inflorescence (spike).

The differentiation and outgrowth of the A2 axis occurrs just after the $\mathrm{Al}$ axis has terminated the production of all its leaves and entered inflorescential development (see also [21]). These facts can be interpreted as the Al axis being morphogenetically domi-

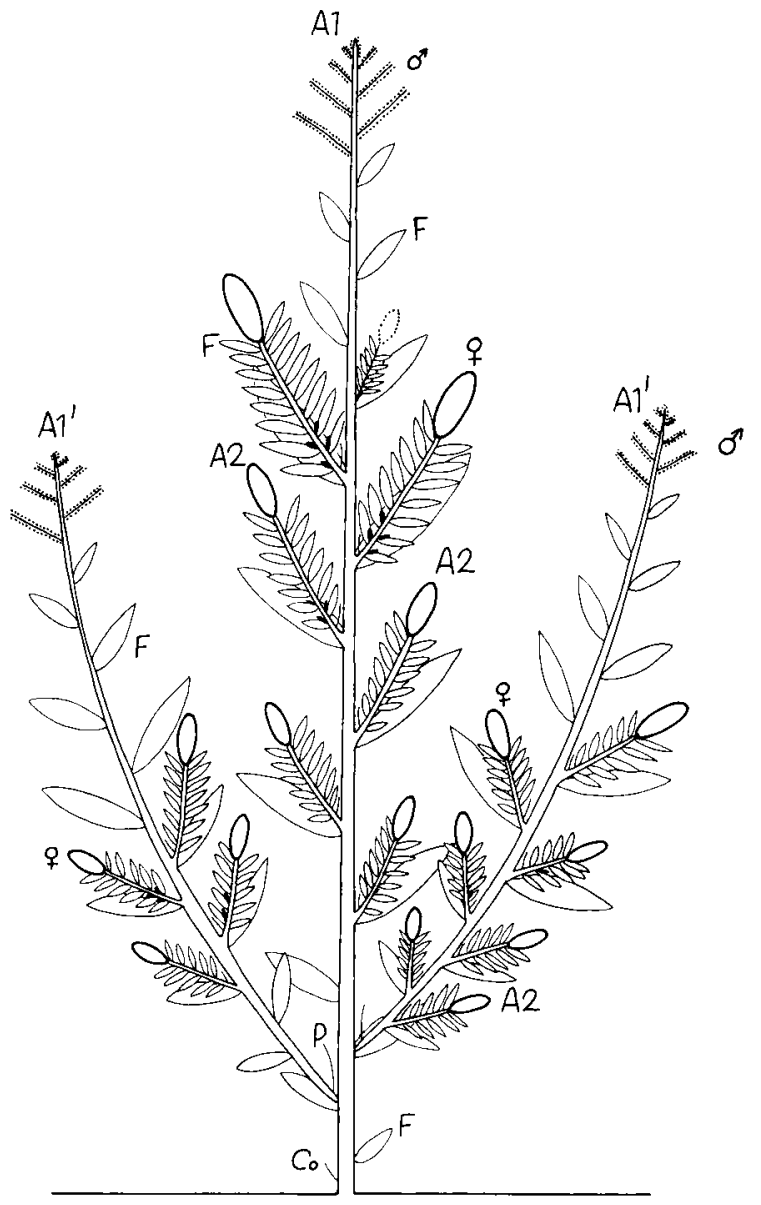

Figure 2. Synthetic diagram of maize architecture (Zea mays L.).

A1, main axis (with a terminal male inflorescence); $\mathrm{Al}$ ', basal reiterate; $A 2$, lateral short axis (with a terminal female inflorescence); $\mathrm{P}$, prophyll; $\mathrm{F}$, leaf; $\mathrm{Co}$, coleoptile.

nant, determining at a certain stage the morphogenesis of the more differentiated $\mathrm{A} 2$ axes. All together, A1 and $\mathrm{A} 2$ axes form a structural unit, which allows the plant to perform all its functions. This unit can thus be interpreted as the 'architectural unit' of the species.

In isolated plants, this architectural unit was not unique. During its growth, the maize plant develops at its base 1-3 long orthotropic axes (figure 2) which are morphologically identical to the main axis (Al type, noted A1'). These axes bear short branches of A2 type, with terminal female inflorescence. These repeated architectural units can therefore be interpreted as resulting from a process of basal reiteration. 
They experienced no quiescent phase in their development, and are thus produced by an immediate branching (sylleptic growth). However, their initial outgrowth was less 'vigorous' (short internodes at their bases) than that of the A2 axes, and they remained hidden in their enclosing sheath much longer.

\subsection{Pea architecture}

Pea is composed of two categories of axes (figure 3). The Al axis is a long monopodial and orthotropic axis, with short basal internodes. Its development is indeterminate and there is no terminal inflorescence. However, the terminal organogenesis is stopped by apical death (the development of pods seem to be partially involved, but the mechanism is still disputed, and positional aspects seem to be important $[18,19])$. The Al axis has a distichous phyllotaxy, and displays secondary growth. At the axil of the three to four most basal true leaves, three buds were found: the main axillary bud (central) and two supernumerary collateral buds. The one or two subsequent nodes usually bore one axillary bud and a single collateral. Then, the upper leaves only had one axillary bud. Globally, the basal part of A1 is vegetative. The terminal part is more complex, with a proximal zone bearing A2 lateral axes, and a distal zone bearing lateral inflorescences (starting around node 15 in this cv.; see [19] for a more general perspective on the development of lateral inflorescences). Rather often, a barren node (without any axillary bud) was found between the basal and the terminal zone.

The A2 axes (figure 3) are short lateral axes, but with a (relatively) long first internode. They are orthotropic and indeterminate, with distichous phyllotaxy. In our experiment, they displayed no supernumerary axillary buds, no secondary growth, and bore lateral inflorescences down to the third node.

The outgrowth of A2 axes started after the development of the first inflorescence in the A1, and thereafter it was immediate and basipetous. A2 axes are always lateral to the Al (figure 3) and display a restricted vegetative development. All these traits indicate that the morphogenesis of $\mathrm{A} 2$ is under the influence of $\mathrm{A} 1$. The ensemble of $\mathrm{A} 1$ and $\mathrm{A} 2$ is moreover functionally complete. It can thus be interpreted as the architectural unit of the species.

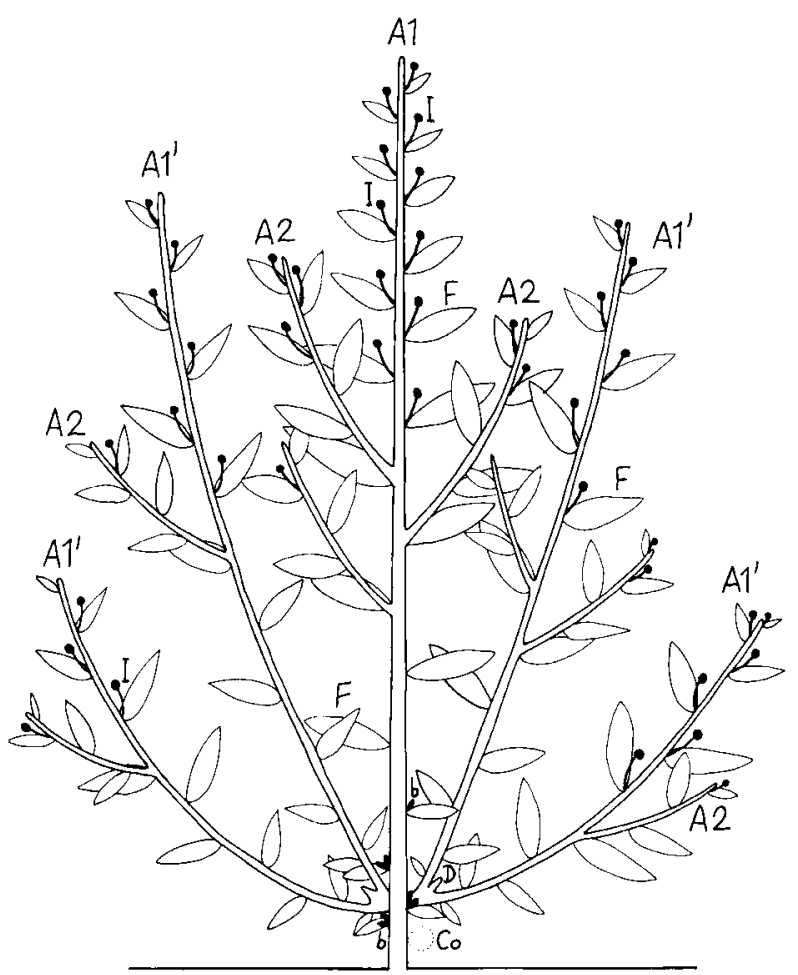

Figure 3. Synthetic diagram of pea architecture (Pisum sativum $\mathrm{L}$.)

$A 1$, main axis; $A 1$ ', basal reiterate; $A 2$, lateral short axis; $F$, leaf; $\mathrm{Co}$, cotyledon; $\mathrm{b}$, quiescent bud; $\mathrm{I}$, inflorescence.

At the basal nodes of A1, large branched systems developed, at least in isolated plants. They were formed by long monopodial orthotropic axes, identical to the main axis A1, and therefore noted A1' figure 3). The basal part of Al' axes is vegetative, with short internodes, and their terminal part bears short laterals and lateral inflorencences. These lateral short axes are of the A2 type, with a long first internode, and bear lateral inflorescences. These basitonic systems thus correspond to reiterates of the architectural unit of the plant. Stricto sensu, their development is immediate (sylleptic growth). However, they experienced a lag before their outgrowth, shown morphologically by their existence as whitish buds in younger plants. In these buds, the leaves were reduced to scale, and the internodes were very short.

\subsection{Architectural variability}

Two types of variability in architectural development can be observed in our experiment: a variability 
between plants within the same density treatment (in particular in the case of the isolated plants, in which the architectural development is much less constrained), and a variability between the isolated and high density treatments. From a developmental point of view, comparing them can be of interest, as both genotypic and plastic variations may result from modulations or perturbations of the same basic morphogenetical dynamics (in our conditions, there was no plant death, so treatments were applied to comparable samples of the same population).

In maize, the architectural variability in isolated plants affected mainly the presence or absence of the more basal reiterate (node 2 ). In dense stands, the basal reiterates were no longer displayed at all (figure 4 ), and are thus facultative. The number of visible A2 also decreased down to the one or two top axes in dense stands, but the 'missing' axes could be found by dissection. These axes had experienced an almost complete organogenesis, down to the development of their inflorescence, but their outgrowth was reduced. In the median zone, they could be reduced to such minute axes that they were still enclosed within their prophyll. In the outgrown A2 axes, in these dense stand conditions, the morphology of the A2 leaves was also changed, with an almost total suppression of lamina expansive growth (however, a minute but clear lamina could be found). The number of vegetative phytomers in A2 also showed significant variability between density treatments.

In pea, the variability in isolated plants concerned the number and origin of the reiterates. In some plants, two A1' were displayed per node. They originated from the collateral buds (figure 1), whereas the central bud had aborted. This process can be more or less repeated leading to 'bushy' plants. This demonstrates that, in pea, in contrast to some other species [1], there is no determination of the collateral buds towards a distinct fate. The origin of this death is unclear. The only clear thing is that it is not systematic. Although this can be interpreted as indicating an accidental origin, the hypothesis of a developmental process is equally arguable, in a genotype displaying abortion of the terminal A1 apex (and also of some axillary apexes). This aspect would thus require a more detailed study. The number of A2 (and the number of reproductive nodes) also varied.
In dense stand conditions, the number of branches of pea plants was strongly decreased. In contrast to maize, however, many plants were found with basal A1' and no A2.

\section{Discussion}

The comparison between maize and pea demonstrates rather unexpected similarities in terms of architectural development, despite their huge phyllogenetical and physiognomical differences. Both of them have two categories of axes, with differentiated morphological and functional characteristics. The structure and the sequence of development of their architectural unit is rather similar. Both species are also capable of basal complete reiterations, duplicating the architectural unit. The development of these reiterates is immediate, basipetous and basitonic, but they experience a phase of retarded growth (compared to the A2 axes). The expression of this basal reiteration is highly dependant on the environment.

Such similarity is of clear interest for architectural modelling. Although the apparent physiognomy of species is different, they can share rather large developmental architectural 'programmes' (basitonic

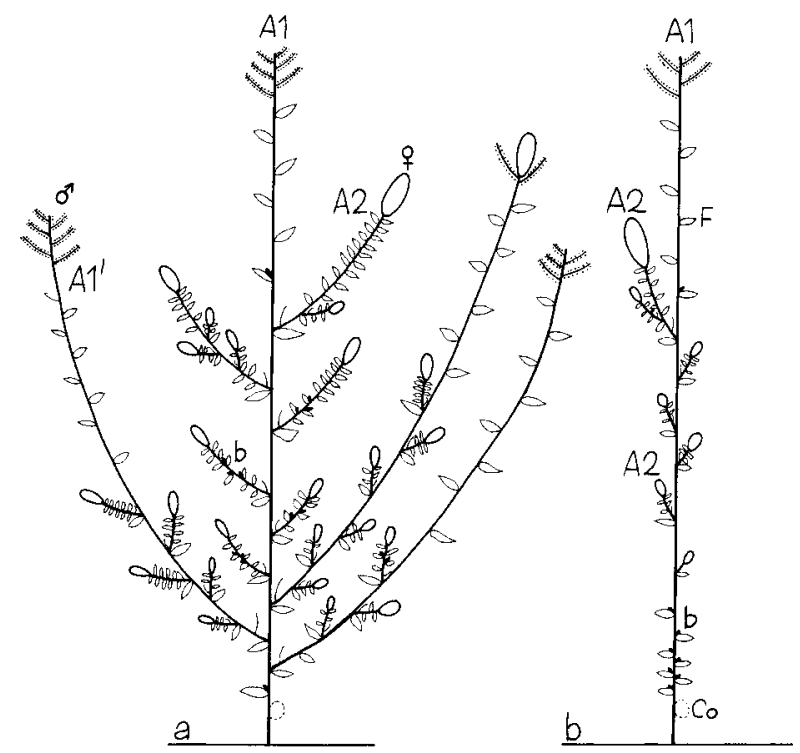

Figure 4. Architectural variability in maize (Zea mays L.). a) Typical isolated plant; b) typical plant from dense stands ('high density'). A1, main axis; A1', basal reiterate; A2, lateral short axis; b, quiescent bud. 
immediate reiteration, acrotonic A2 differentiation). Interestingly, these similarities do not lie at the phytomeric level, as the phytomers have very distinct shapes and topology in the two species. They also extend beyond the basic shoot iterative phytomeric production that has already been captured by these models for herbs (e.g. [7, 20]), and come mainly from the macro-characters of axe differentiation and of reiteration. This illustrates the fact that the development of plants includes repetition at various complexity levels, allowing us to define natural, heterogeneous compartments at various scales (see [6] for a more general discussion of this aspect of plant organisation). It will be of particular interest to investigate in a broader range of species the possibility of deducing a typology in the modes of construction of the architectural unit (axis differentiation and sequence of outgrowth), and in the modes of reiteration. Incidentally it should also be noted that the models of branching currently available for crop plants (the so-called 'tillering models' developed for grasses $[3,14]$ ) have to be extended to cope with the more complex branching pattern reported here.

By the same token, the existence of these similarities also indicates that specific terminology can sometimes act as a possible obstacle in architectural studies. This is for example the case of the term 'tiller' that is only used for grasses. It seems to define a particular type of organ, whereas it only refers to normal axes. It might even be rather ambiguous, as it is not clear whether it points to the possibility of vegetative multiplication or not. It is hoped that subsequent studies on other Poaceae species will allow us to better clarify this aspect [20]. Meanwhile, the tillers of maize are complete reiterates, and from that perspective are comparable to the basal branches of pea (see [6] for a more general discussion about the root system of complete shoot reiterates). Note lastly that a similar discussion could be held for example for the term "ear shank' in maize.

From this limited study of two crop species, the framework of architectural analysis thus seems to apply to the study of herbs, and to be particularly useful for inter-specific comparisons. It is noteworthy that such a rather qualitative but cautious morphological observation, when centred on the analysis of the plant architectural development, proved informative and provided a starting point for more detailed studies. However, when compared to angiosperm trees, the categories of axes are much less differentiated, and less numerous. For that reason, the contribution of architectural analysis to the understanding of development for a given species is less spectacular than in trees (beyond that of 'standard' morphology).

Concerning the effect of environment, and particularly of plant density, the most clear fact is that a conspicuous reiterative branching can occur when plant are carefully isolated. This is particularly spectacular in maize, as Dea is a modern cultivar, known to be non-tillering and non-prolific [23]. It demonstrates that the reduction of reiterative branching by plant breeding did not result from a genetic suppression of the reiteration capacity, but from an increased sensibility to neighbouring plants. Note additionally that reiterative branching was also variable between plants of the same genotype in isolated conditions. This demonstrates the value of a co-operative research in developmental genetics, architecture and ecophysiology (particularly environmental signals). Moreover, this means that if architectural models are to encompass a much larger range of environmental conditions than current process models, down to the isolated plants that breeders manipulate, it will be necessary to take this facultative reiteration into account, even in species where it is a negligible component of yield in standard agricultural conditions.

The relevance of the axis types in terms of their response to environment, if rather clear within a single species (and particularly in the case of maize), is less substantiated at the inter-specific level. Increased stand density suppresses first the Al' reiterates in maize (although they develop before the A2), but this seems to be the contrary in pea, where A2 axes are more reduced. This question has to be investigated more deeply, to test for example the importance of traumatic reiteration in pea, or the influence of the kinetic of shading development in dense stands compared to that of potential reiteration. Whatever the case, this contrasted behaviour points to interesting questions: i) the possibility of various modes of axis differentiation and of morphogenesis of the architectural unit [16], and ii) their consequences in term of ecophysiological functioning. Advances in this direction will clearly come from the comparative study of 
several species, and architectural modelling can be particularly useful as a tool to test various hypothetical scenarios. This will no doubt benefit from the interdisciplinary interest, making comparative ecophysiology and architecture of herbs a promising field.

Acknowledgement: This work reviews a part of the results obtained within a research project 'Architectural dynamics in cultivated herbs and its modulation by physical environment' funded by Inra through its AIP Ecofon. The authors thank the other scientists in the project, working on other plants or on modelling, (J.-M. Allirand, B. Andrieu, M. Chartier, J.-L. Durand, C. Fournier, H. Gautier, C. Varlet-Grancher) for invigorating discussions. A special thanks to P. Bonchretien and M. Laurensot for technical support.

This article corresponds to no. 98-094 of the Institut des sciences de l'evolution (UMR 5554 of CNRS) which sustained this research.

\section{References}

[1] Bell A.D., Plant form - An Illustrated Guide to Flowering Plant Morphology, Oxford University Press, Oxford, UK, 1991, pp. 341.

[2] Bonhomme R., Drouet J.-L., Améglio T., Introduction à la modélisation du fonctionnement physiologique d'un couvert, in: Cruiziat P., Lagouarde J.-P., (Eds.), Actes de l'École-Chercheur Inra en Bioclimatologie, tome 1: De la plante au couvert, Inra, Paris, 1995, pp. 647-667.

[3] Bos H.J., Neuteboom J.H., Morphological analysis of leaf and tiller number dynamics of wheat (Triticum aestivum L.): responses to temperature and light intensity, Ann. Bot. 81 (1998) 131-139.

[4] De Reffye P., Edelin C., Françon J., Jaeger M., Puech C., Plant models faithfull to botanical structure and development, Comput. Graphics 22 (1988) 151-158.

[5] Edelin C., Nouvelles données sur l'architecture des arbres sympodiaux: le concept de plan d'organisation, in: Edelin C. (Ed.), Compte rendu du colloque « L'arbre, biologie et développement », Montpellier, 10-15 September 1990, Naturalia monspeliensia (suppl.) (1991) 127-154.

[6] Edelin C., Moulia B., Tabourel F., Notions d'analyse architecturale des plantes, in: Cruiziat P., Lagouarde J.-P. (Eds.), Actes de l'École-Chercheur Inra en Bioclimatologie, tome 1: De la plante au couvert, Inra, Paris, 1995, pp. 83-106.

[7] Fournier C, Andrieu B., A 3D architectural and process-based model of maize development, Ann. Bot. 81 (1998) 233-250.

[8] Gautier H., Varlet-Grancher C., Baudry N., Comparison of horizontal spread of white clover (Trifolium repens $\mathrm{L}$.) grown under two artificial light sources differing in their content of blue light, Ann. Bot. 82 (1998) 41-48.

[9] Hallé F., Oldeman R.A.A., Tomlinson P.B., Tropical Trees and Forests, an Architectural Analysis, SpringerVerlag, New York, USA, 1978, pp. 441.

[10] Jeannoda-Robinson V., Contribution à l'étude de l'architecture des herbes, thèse, $U$. des sciences et techniques du Languedoc, Montpellier, France, 1977.

[11] Klepper B., Belford R.K., Peterson C.M., Quantitative characterization of vegetative development in small cereal grains, Agronomy J. 74 (1982) 789-792.

[12] Ledent J.F., Henkart T., Jacobs B., Phénologie du mais, visualisation de la croissance et du développement, Rev. Agric. 43 (1990) 391-408.

[13] Loup C., Essai sur le déterminisme de la variabilité architecturale des arbres (cas de quelques espèces tropicales), thèse, université de Montpellier 2, Montpellier, France, 1994.

[14] Masle J., Competition among tillers in winter wheat: consequences for growth and development of the crop, in: Day W., Atkin R.W. (Eds.), Wheat Growth and Modelling, Plenum Press, NATO ASI Series A Life Science 86, New York, USA, 1984, pp. 33-53.

[15] Moulia B., Edelin C., Jeuffroy M.H., Allirand J.-M., Loup C., Chartier M., Premiers éléments d'analyse du développement architectural des herbacées cultivées, in: Maillard P., Bonhomme R. (Eds.), Fonctionnement des plantes sous contraintes environnementales, Inra, Paris, 1999, in press

[16] Nozeran R., Bancilhon L, Neville P., Intervention of internal correlations in the morphogenesis of higher plants, Adv. Morphog. 9 (1971) 1-66.

[17] Oldeman R.A.A., L'architecture de la forêt guyanaise, Mémoire Orstom no. 73, IRD, Paris, France, 1974.

[18] Pate J.S., Pea, in: Evans L.T. (Ed.), Crop Physiology, Cambridge University Press, Cambridge, UK, 1975, pp. 191-224.

[19] Roche R., Jeuffroy M.H., Ney B., A model to simulate the final number of reproductive nodes in pea (Pisum sativum L.), Ann. Bot. 81 (1998) 545-555.

[20] Room P.M., Maillette L., Hanan J.S., Module and metamer dynamics and virtual plants, Adv. Ecol. Res. 25 (1994) 105-157.

[21] Ruget F., Duburcq J.B., Développement reproducteur des bourgeons axillaires chez le maïs: stades de différenciation, nombre de fleurs, Agronomie 3 (1983) 797-808.

[22] Sharman B.C., Developmental anatomy of the shoot of Zea mays L., Ann. Bot. 6 (1942) 245-282.

[23] Sonohat-Popa G., Analyse des variations de structure aérienne des peuplements de maïs dans différentes conditions de compétition intraspécifique, thèse, université d'Orsay, Orsay, France, 1997. 